\section{UJMM

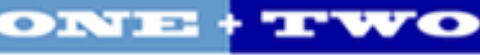

Volume 3 | 2011 Spring

\section{Undergraduate Journal of Mathematical}

Modeling: One + Two

2011

\title{
Study of Consciousness
}

Samuel Lee

University of South Florida

Advisors:

Arcadii Grinshpan, Mathematics and Statistics

Andrei Chugunov, Fortis College: Medical Sciences

Problem Suggested By: Andrei Chugunov

Follow this and additional works at: https://digitalcommons.usf.edu/ujmm

Part of the Mathematics Commons

UJMM is an open access journal, free to authors and readers, and relies on your support:

Donate Now

\section{Recommended Citation}

Lee, Samuel (2011) "Study of Consciousness," Undergraduate Journal of Mathematical Modeling: One + Two: Vol. 3: Iss. 2, Article 11.

DOI: http://dx.doi.org/10.5038/2326-3652.3.2.11

Available at: https://digitalcommons.usf.edu/ujmm/vol3/iss2/11 


\title{
Study of Consciousness
}

\begin{abstract}
The human brain is a powerful organ that controls most of the body. Researchers around the world have long tried to uncover how the brain operates, how memories are formed and stored. Our understanding of neurological diseases such as Alzheimer's and Parkinson's disease has been rapidly improving, yet much remains to be done. In this work, we attempt to study changes in intracranial pressure (ICP) for a 12-hour period and discuss whether the resulting estimates could be used as a measure of consciousness.
\end{abstract}

\section{Keywords}

Neurology, Consciousness, Intracranial Pressure

\section{Creative Commons License}

(c) (i) ()

This work is licensed under a Creative Commons Attribution-Noncommercial-Share Alike 4.0 License. 


\section{TABLE OF CONTENTS}

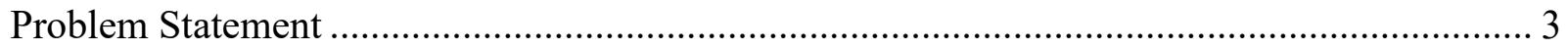

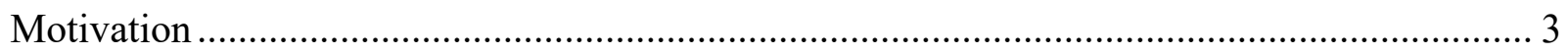

Mathematical Description and Solution Approach ................................................... 3

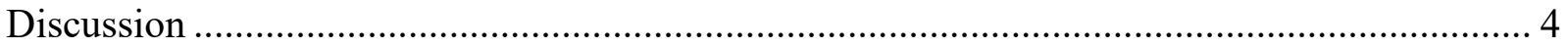

Conclusion and Recommendations .................................................................................. 5

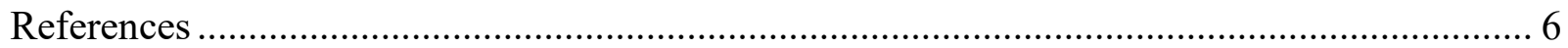

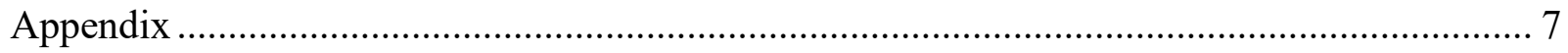




\section{PROBLEM STATEMENT}

The human brain is arguably the most important organ in our body, yet many of its properties remain unknown. By virtue of this uncertainty, defining, let alone studying complex concepts such as consciousness remains extremely difficult. We attempt to approach the problem of quantifying consciousness by assuming that it can be related to changes in intracranial pressure (ICP).

\section{MOTIVATION}

Many researchers are trying to better understand the inner workings of the human brain. Some doctors and pharmaceutical companies claim that they possess different medications and methods that improve brain function, yet many have negative side effects (Talbot, 2009). This suggests that there are significant gaps in our understanding of how the brain functions. However, as we improve our understanding of processes such as consciousness, we can, in turn, better understand the brain and find ways to increase brain function (K, McGovern, 2005).

Although we can only speculate about the correct ways of studying consciousness, in this work we discuss using intracranial pressure for this purpose. In our estimates, we used the data from (Lin \& Liu, 2010).

\section{MATHEMATICAL DESCRIPTION AND SOLUTION APPROACH}

After examining the data concerning intracranial pressure in rats (Lin \& Liu, 2010) and converting it into a scatter plot (time as the $x$-axis and intracranial pressure as the $y$-axis), it became apparent that neither linear nor exponential functions would not fit the data in Figure 1. 
Therefore, we've tried other classes of functions. Among the examined classes, the functions of the form $P(t)=a \cdot \cos (b \cdot t+c)+d \cdot \sin (e \cdot t+f)+g$ fitted the data best. The actual fitting was performed using the least squares method (programmed in Excel) and the obtained values of the constants $a, b, c, d, e, f$, and $\mathrm{g}$ are displayed in Table 1. The obtained best-fit line is graphed in Figure 1.

\begin{tabular}{|ccc|c|}
\hline$t$ & $y$ & $P(t)$ & $(\boldsymbol{y}-\boldsymbol{P}(\boldsymbol{t}))^{2}$ \\
\hline 0 & 9.25 & 9.21 & 0.001 \\
\hline 1 & 9.20 & 9.35 & 0.024 \\
\hline 2 & 9.35 & 10.03 & 0.470 \\
\hline 3 & 7.50 & 8.38 & 0.785 \\
\hline 4 & 8.25 & 8.97 & 0.529 \\
\hline 5 & 10.85 & 10.66 & 0.035 \\
\hline 6 & 8.85 & 8.54 & 0.090 \\
\hline 7 & 9.25 & 8.68 & 0.314 \\
\hline 8 & 10.15 & 10.12 & 0.001 \\
\hline 9 & 9.50 & 9.18 & 0.097 \\
\hline 10 & 9.55 & 9.21 & 0.110 \\
\hline 11 & 9.45 & 8.93 & 0.265 \\
\hline 12 & 9.55 & 9.36 & 0.033 \\
\hline
\end{tabular}

\begin{tabular}{|cc|}
\hline Constants & Calculated Values \\
\hline$a$ & 0.669 \\
\hline$b$ & 8.589 \\
\hline$c$ & 1.220 \\
\hline$d$ & 0.721 \\
\hline$e$ & 4.588 \\
\hline$f$ & -2.697 \\
\hline$g$ & 9.292 \\
\hline \multicolumn{2}{c}{} \\
\hline
\end{tabular}

Table 1: Summary of the least squares method applied to the function $\boldsymbol{P}(\boldsymbol{t})$, where $\boldsymbol{t}$ is the time (in hours) starting at 6:00pm and ending at 6:00am and $\boldsymbol{y}$ is the corresponding value of the target function.

\section{DISCUSSION}

The scatter plot demonstrates the periodic nature of intracranial pressure (ICP). An extrapolation could be made that as ICP changes, so does the memory function. In addition, much of the pressure fluctuates during the middle of the day possibly due to increased or peak activity (Figure 1) and the pressure levels out toward the end of the day (Figure 1). On the scatter plot (Figure 1) this trend is not very clear, however the obtained equation helps to predict these features. After the function was superimposed on the scatter plot (see Figure 1), one can see that 
the scatter points fit the function reasonably well. As a result, a typical consciousness function could be estimated the trigonometric function of the form

$$
P(t)=a \cdot \cos (b \cdot t+c)+d \cdot \sin (e \cdot t+f)+g
$$

under the assumption that the consciousness is proportional to the intracranial pressure.

\section{CONCLUSION AND RECOMMENDATIONS}

The result of this project is a trigonometric function that models ICP changes and potentially could be used to study consciousness. While it is difficult to predict minimum and maximum values of HSP from our function, one can say that during the day after several hours of activity, ICP fluctuates the most and is relatively stable right after waking and before resting. The results of this project are limited by assumptions; such as whether the data obtained for rats could be used to make predictions about humans. While one may find the use of rat data a stretch, there is a study to support that a rat's brain operates and develops in a similar fashion to that of humans (Bayer et al., 1993). Furthermore, rats make decisions in a very similar manner to humans; therefore, allowing for the crude comparison between rat ICP and human ICP (Raposo et al., 2012). 


\section{REFERENCES}

Bayer, S. A., Altman, J., Russo, R. J., \& Zhang, X. (1993). Timetables of neurogenesis in the human brain based on experimentally determined patterns in the rats. NeuroToxicology, 14(1), 83-144.

Karel Pieterse, J. (2012). Fitting curves to your data using least squares. Retrieved from http://www.jkp-ads.com/articles/leastsquares.asp

McGovern, K. M. (2005). The Effects of Exercise on the Brain. Web. 5 May 2011. $<$ http://serendip.brynmawr.edu/bb/neuro/neuro05/web2/mmcgovern.html>.

Larson, R., Hostetler, R., Edwards, B. (2005) Calculus. 8th Edition. Boston, MA: Houghton Mifflin Company.

Lin, Jessica S., Liu, John H. K. (2010) Circadian Variations in Intracranial Pressure and Translaminar Pressure Difference in Sprague-Dawley Rats. Invest. Ophthalmol. Vis. Sci. $51(11), 5739-5743$.

Raposo, D., Sheppard, J. P., Schrater, P. R., \& Churchland, A. K. (2012). Multisensory decisionmaking in rats and humans. The Journal of Neuroscience, 32(11), 3726-3735.

Sensation and Perception. Society for Neuroscience. Web. 4 May 2011. $<$ www.sfn.org/skins/main/pdf/brainfacts/.../sensation_perception.pdf $>$.

Talbot, M. (2009, September 20). Can a daily pill really boost your brain power?. The Guardian. Retrieved from http://www.guardian.co.uk/science/2009/sep/20/neuroenhancers-us-brainpower-drugs. 


\section{APPENDIX}

\section{Intracranial Pressure with Best-Fit Curve}

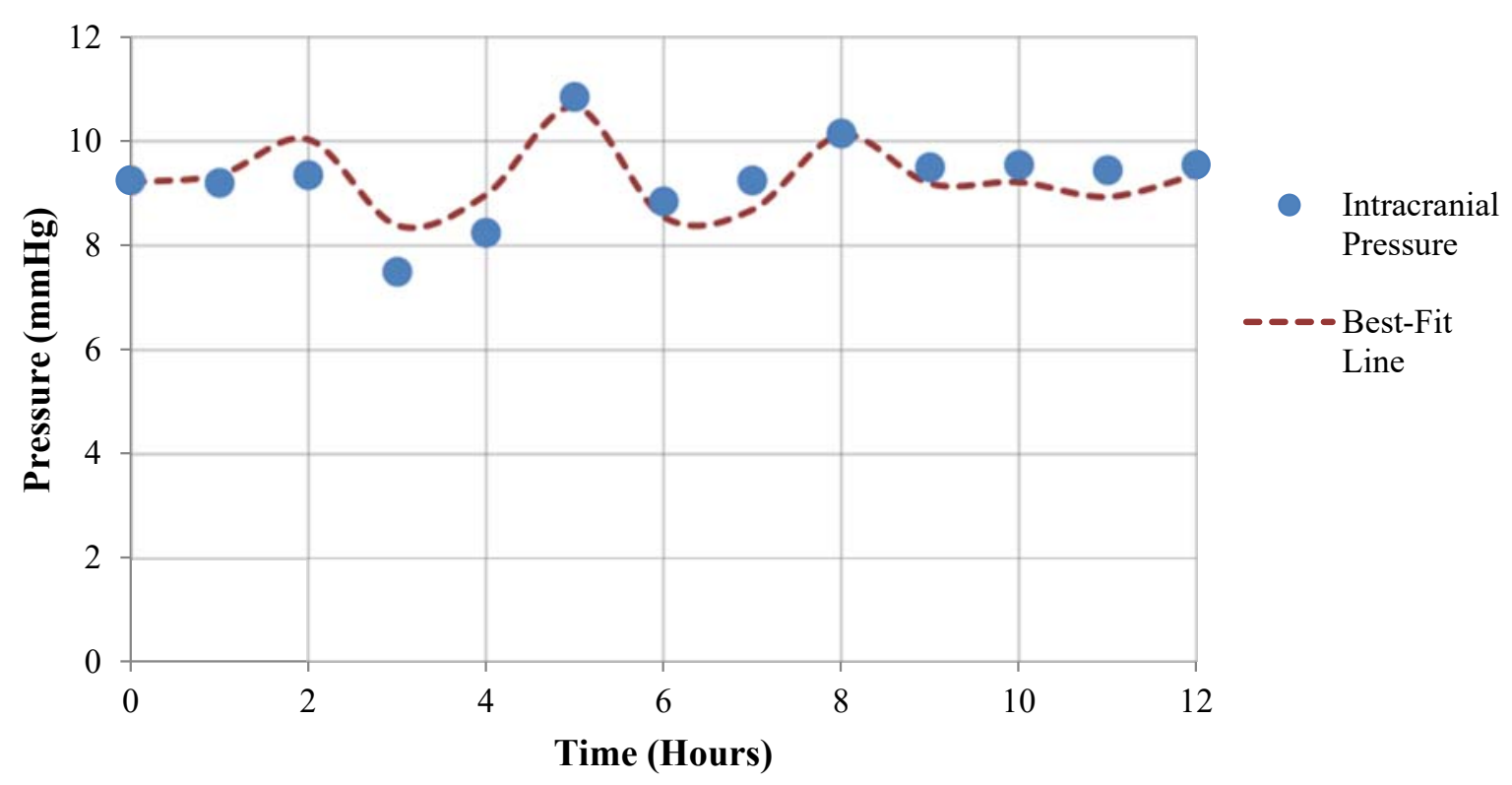

Figure 1: Relationship between time (starting at 6:00am) and intracranial pressure (estimated from (Lin \& Liu, 2010)) along with the estimated curve of the bestfit. Here $\boldsymbol{t}=\mathbf{0}$ corresponds to the time interval $6-7 \mathrm{pm}$ and $\boldsymbol{t}=\mathbf{1 2}$ to $5-6 \mathrm{am}$. 